[Supporting Information]

\title{
Dual-Functionalized Fluorescent Cationic Organic Network: Highly Efficient Detection and Removal of Dichromate from Water
}

Zhi-Jun Li, ${ }^{,}{ }^{\dagger}$ Hua-Dong Xue, ${ }^{\ddagger}$ Yun-Xiang Ma, ${ }^{P}$ Qi Zhang,,${ }^{\dagger}$ Yan-Chun Li, ${ }^{\dagger}$ Miao Xie, ${ }^{\dagger}$ Hui-Li Qi, ${ }^{\dagger}$ and Xu-Dong Zheng ${ }^{*}{ }^{\dagger}$

† College of Chemistry and Chemical Engineering, Longdong University, Qingyang, Gansu, 745000, P. R. China.

* State Key Laboratory of Applied Organic Chemistry, College of Chemistry and Chemical Engineering, Lanzhou University, Lanzhou, Gansu 730000, P. R. China.

PCollege of Food Science and Engineering, Gansu Agricultural University, Lanzhou, Gansu, 730070, P. R. China.
A. Summary of Figures and Tables
S-2
B. Materials and Instrumentation
C. Synthetic Procedure S-5
D. FT-IR Spectra S-6
E. ${ }^{13} \mathrm{C}$ CP-MAS NMR Spectra S-7
F. Powder X-ray Diffraction Analysis S-8
G. $\mathrm{N}_{2}$ Adsorption-Desorption Analysis S-9
H. Thermogravimetric Analysis
I. Scanning Electron Micrograph
J. X-ray Photoelectron Spectroscopy
K. Fluorescence Detection of $\mathrm{Cr}_{2} \mathrm{O}_{7}{ }^{2-}$
L. Adsorption of $\mathrm{Cr}_{2} \mathrm{O}_{7}{ }^{2-}$
M. References 


\section{A. Summary of Figures and Tables}

Fig. S1 FT-IR spectra of CON-LDU2 and the starting materials S-6

Fig. S2 FT-IR spectra of CON-LDU2, CON-LDU2-Cr, and Regenerated S-6 CON-LDU2

Fig. S3 $\quad{ }^{13} \mathrm{C}$ CP-MAS NMR spectra of CON-LDU2 and CON-LDU2-Cr $\quad$ S-7

Fig. S4 Powder X-ray diffraction pattern of CON-LDU2 S-8

$\begin{array}{lll}\text { Fig. S5 } & \mathrm{N}_{2} \text { adsorption and desorption isotherms of CON-LDU2 S-9 }\end{array}$

$\begin{array}{lll}\text { Fig. S6 Pore-size-distribution of CON-LDU2 } & \text { S-9 }\end{array}$

$\begin{array}{llr}\text { Fig. S7 BET surface area plot for CON-LDU2 } & \text { S-10 }\end{array}$

$\begin{array}{llr}\text { Fig. S8 TGA curve of CON-LDU2 } & \text { S-11 }\end{array}$

$\begin{array}{llr}\text { Fig. S9 SEM image of CON-LDU2 S-12 } & \text { S }\end{array}$

Fig. S10 XPS spectra of CON-LDU2, CON-LDU2-Cr, and Regenerated S-13 CON-LDU2

Fig. S11 Fluorescence spectra of CON-LDU2 in solid state and dispersed in S-15 water

Fig. S12 Stern-Volmer plot of CON-LDU2 quenched by $\mathrm{Cr}_{2} \mathrm{O}_{7}{ }^{2-} \quad \mathrm{S}-15$

Fig. S13 The linear fitting for the fluorescence intensities of CON-LDU2 ver- S-16 sus the concentration of $\mathrm{Cr}_{2} \mathrm{O}_{7}^{2-}$

Fig. S14 The fluorescence intensities of CON-LDU2 in the presence of com- S-16 peting anions, and in the presence of competing anions and $\mathrm{Cr}_{2} \mathrm{O}_{7}{ }^{2-}$

$\begin{array}{llr}\text { Fig. S15 The kinetics for adsorption of } \mathrm{Cr}_{2} \mathrm{O}_{7}{ }^{2-} & \text { S-19 }\end{array}$

Fig. S16 The adsorption isotherm of $\mathrm{Cr}_{2} \mathrm{O}_{7}{ }^{2-}$ fitted with different models. $\quad$ S-20

Fig. S17 The weight residual percentages of CON-LDU2 in aqueous solution S-21 with different $\mathrm{pH}$ values

Fig. S18 Zeta potentials of CON-LDU2 at different $\mathrm{pH}$ values $\quad$ S-21

Fig. S19 The adsorption percentages for $\mathrm{Cr}(\mathrm{VI})$ at different $\mathrm{pH}$ values $\quad$ S-22

$\begin{array}{lll}\text { Tab. S1 Comparison of } \mathrm{Cr}_{2} \mathrm{O}_{7}{ }^{2-} \text { adsorption capacity S-23 } & \text { C }\end{array}$ 


\section{B. Materials and Instrumentation}

\section{Materials}

All chemicals and solvents were purchased from commercial sources and used without further purification.

\section{Instrumentation}

Elemental analysis was performed on a VarioEL V3.00 elemental analyzer (Elementar Analysensysteme $\mathrm{GmbH}$ ).

Fourier transform Infrared (FT-IR) spectra were recorded by using a Shimadzu 8400S instrument.

Solid-state NMR measurements were carried out on a Bruker WB Avance II 400 $\mathrm{MHz}$ spectrometer. The ${ }^{13} \mathrm{C}$ CP-MAS NMR spectra were recorded with a 4-mm doubleresonance MAS probe and with a sample spinning rate of $10.0 \mathrm{kHz}$; a contact time of 2 ms (ramp 100) and a pulse delay of $3 \mathrm{~s}$ were applied.

Powder X-ray diffraction (PXRD) data was collected on a PANalytical X'Pert Pro Diffractometer operated at $40 \mathrm{kV}$ and $40 \mathrm{~mA}$ with $\mathrm{Cu} \mathrm{K} \alpha$ radiation (step size of $0.017^{\circ}$, step time of $8.40 \mathrm{~s})$.

The nitrogen adsorption and desorption isotherms were measured at $77 \mathrm{~K}$ using a Micromeritics ASAP 2020M system. The surface area was calculated from the adsorption data using Brunauer-Emmett-Teller (BET) method. The pore-size-distribution was calculated from the adsorption branch by using non-local density functional theory (NLDFT) method.

The thermogravimetric analysis (TGA) was performed on a Perkin Elmer instrument over the temperature range of 50 to $600{ }^{\circ} \mathrm{C}$ with a heating rate of $10{ }^{\circ} \mathrm{C} / \mathrm{min}$ under nitrogen atmosphere.

Scanning Electron Micrograph (SEM) images were achieved with a Hitachi S-4800 microscope operated at an accelerating voltage of $5.0 \mathrm{kV}$. The sample was prepared by dropping the suspension of material in ethanol on a silicon pellet, then dried and coated with gold.

X-ray photoelectron spectroscopy (XPS) data were recorded with an ESCALAB 
250Xi spectrometer (ThermoFisher Scientific).

UV-Vis spectra were recorded on an Agilent Cary 60 Spectrophotometer.

All the fluorescence spectra were recorded on a F-7000 FL Spectrophotometer at room temperature with a scan speed of $1200 \mathrm{~nm} / \mathrm{min}$, a PMT Voltage of $700 \mathrm{~V}$, and slit width for both excitation and emission of $5 \mathrm{~nm}$.

Zeta potentials of the sample were obtained by using Zeta-Pals Zeta Potential Analyzer (BIC, Brookhaven). 


\section{Synthetic Procedure}

Synthesis of $\mathrm{CON}-\mathbf{L D U} \mathbf{2}$

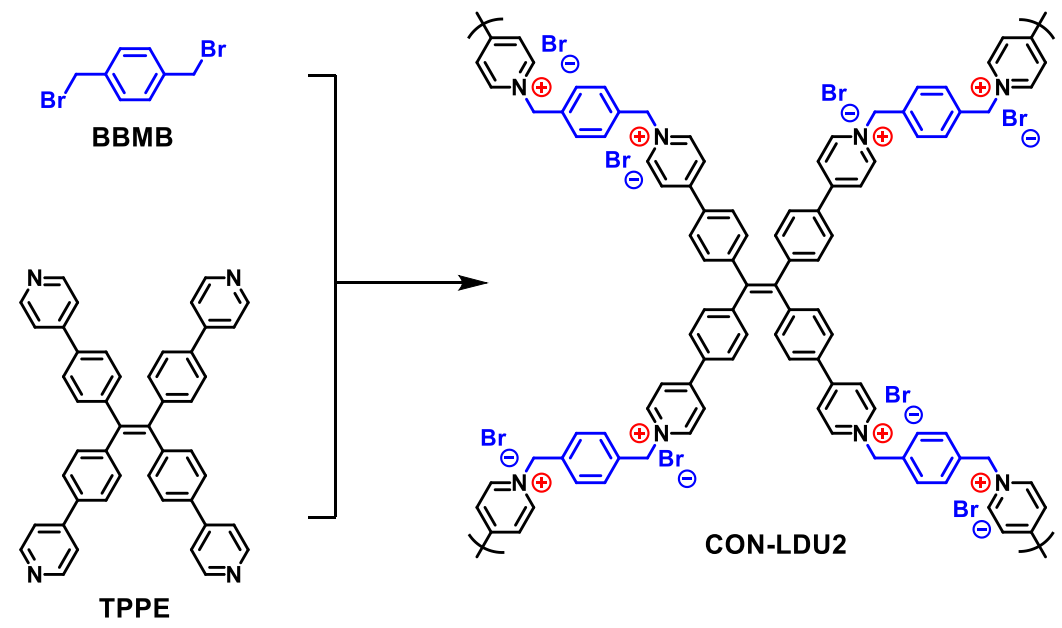

Tetrakis(4-pyridylphenyl)ethylene (TPPE, $64 \mathrm{mg}, 0.1 \mathrm{mmol}$ ) and 1,4-bis(bromomethyl)benzene (BBMB, $53 \mathrm{mg}, 0.2 \mathrm{mmol}$ ) were weighed into a round-bottom flask respectively. The solvent N-methylpyrrolidone (NMP, $5 \mathrm{~mL}$ ) was added via injection under nitrogen atmosphere. The reaction mixture was stirred at $80{ }^{\circ} \mathrm{C}$ for $72 \mathrm{~h}$ in an oil bath. After being cooled to room temperature, the solid was filtered and washed with DMF, water, THF, acetone, ethanol, then dried at $80{ }^{\circ} \mathrm{C}$ for $8 \mathrm{~h}$. Further purification was conducted via Soxhlet extraction with methanol for 48 h. CON-LDU2 was obtained as orange-yellow solid powder, $108 \mathrm{mg}$, yield: 92\%. Elemental analysis (\%): Calcd. for $\left[\mathrm{C}_{62} \mathrm{H}_{48} \mathrm{Br}_{4} \mathrm{~N}_{4}\right]: \mathrm{C} 63.72 ; \mathrm{H} 4.14 ; \mathrm{N}$ 4.79. Found: C 59.58; H 4.59; N 4.67. 


\section{FT-IR Spectra}

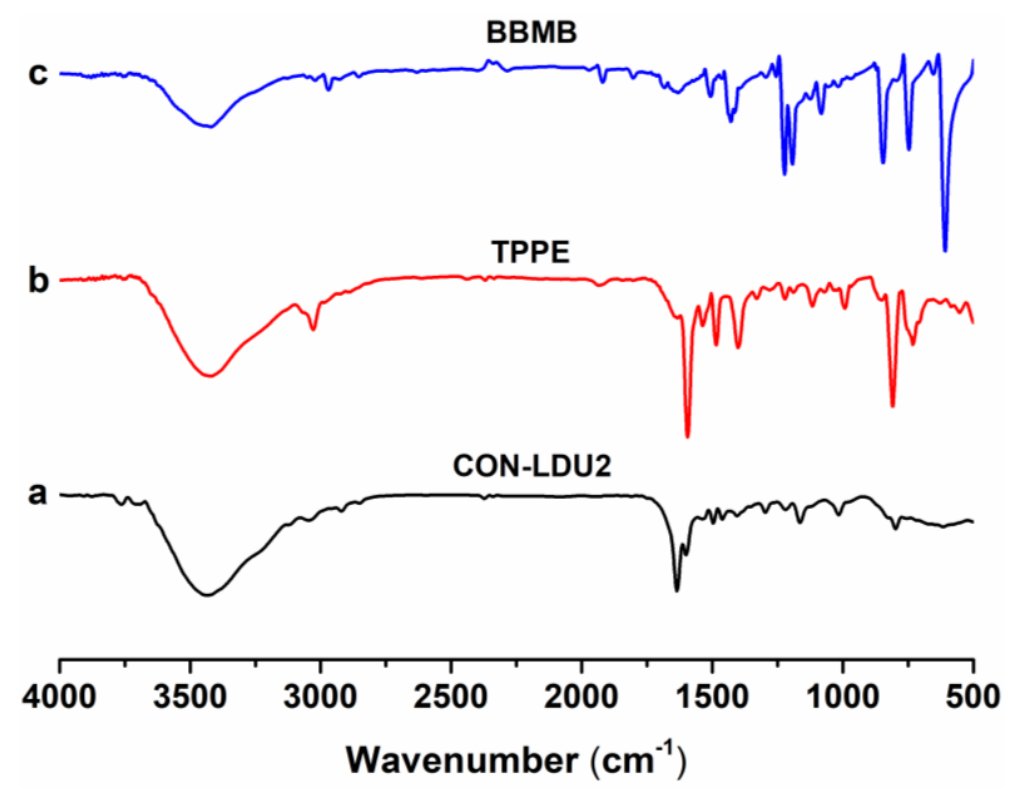

Figure S1. FT-IR spectra of CON-LDU2 (a), tetrakis(4-pyridylphenyl)ethylene (b, TPPE), and 1,4-bis(bromomethyl)benzene (c, BBMB).

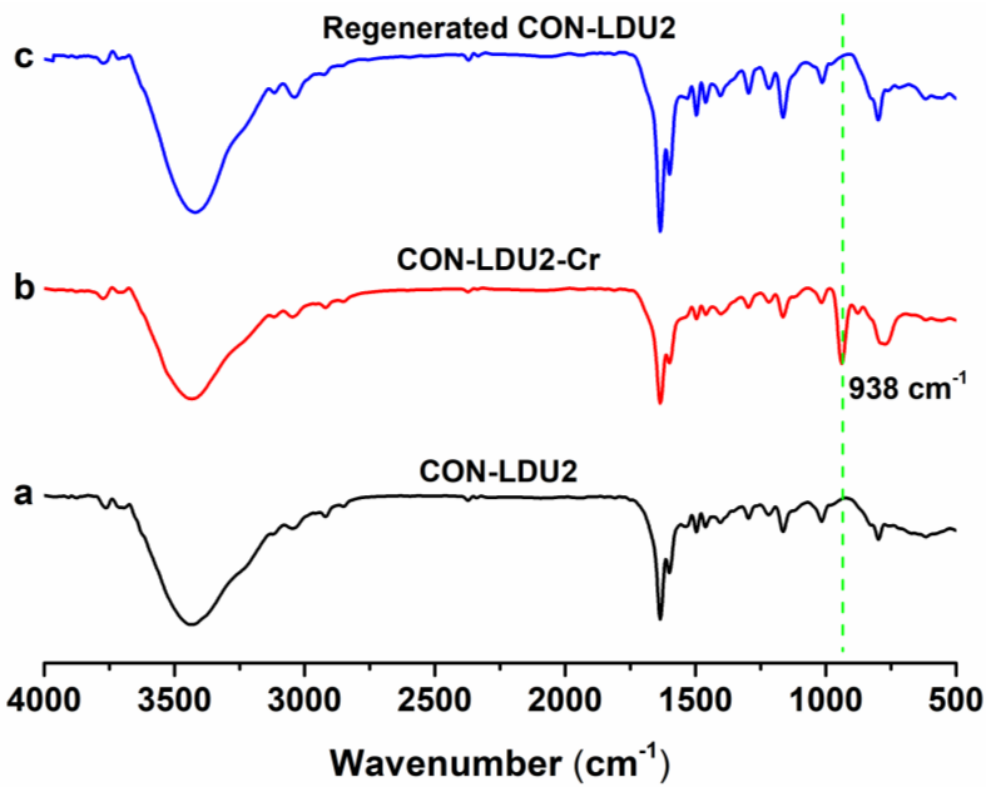

Figure S2. FT-IR spectra of CON-LDU2 (a), CON-LDU2-Cr (b), and Regenerated CON-LDU2 (c). 


\section{E. ${ }^{13}$ C CP-MAS NMR Spectra}

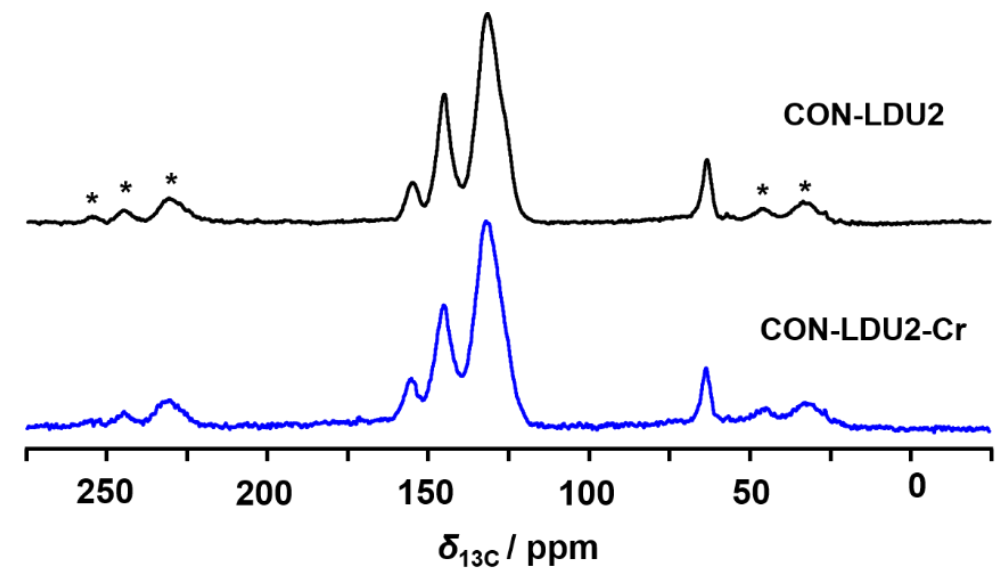

Figure S3. Solid state ${ }^{13} \mathrm{C}$ CP-MAS NMR spectra of CON-LDU2 and CON-LDU2Cr. The asterisks denote the spinning sidebands. The almost identical NMR spectra implied the structure preservation of CON-LDU2 after adsorption of $\mathrm{Cr}_{2} \mathrm{O}_{7}{ }^{2-}$. 
F. Powder X-ray Diffraction Analysis

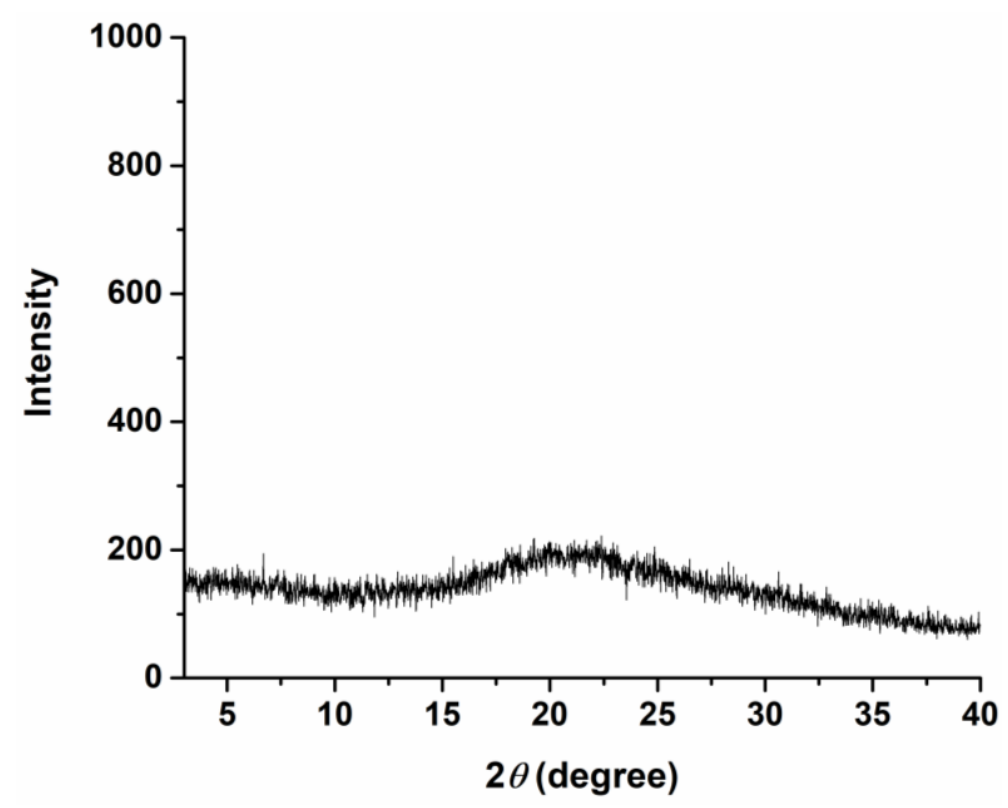

Figure S4. Powder X-ray diffraction (PXRD) pattern of CON-LDU2. 


\section{G. $\mathbf{N}_{2}$ Adsorption-Desorption Analysis}

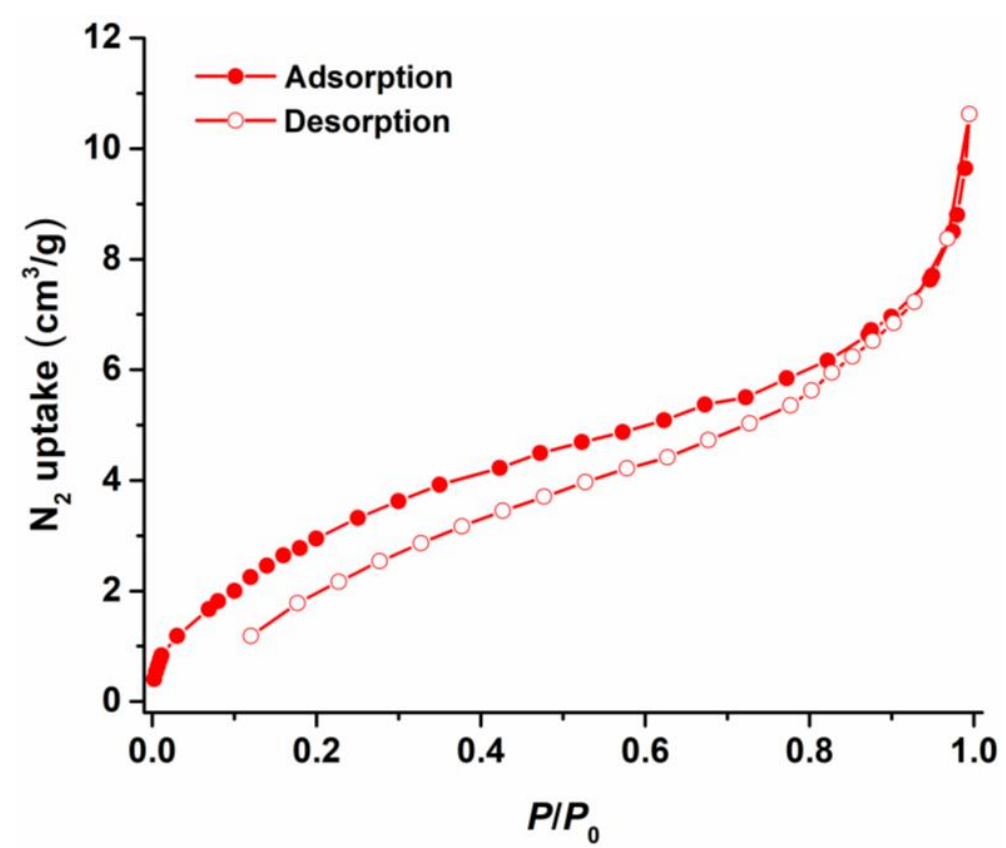

Figure S5. $\mathrm{N}_{2}$ adsorption and desorption isotherms of CON-LDU2.

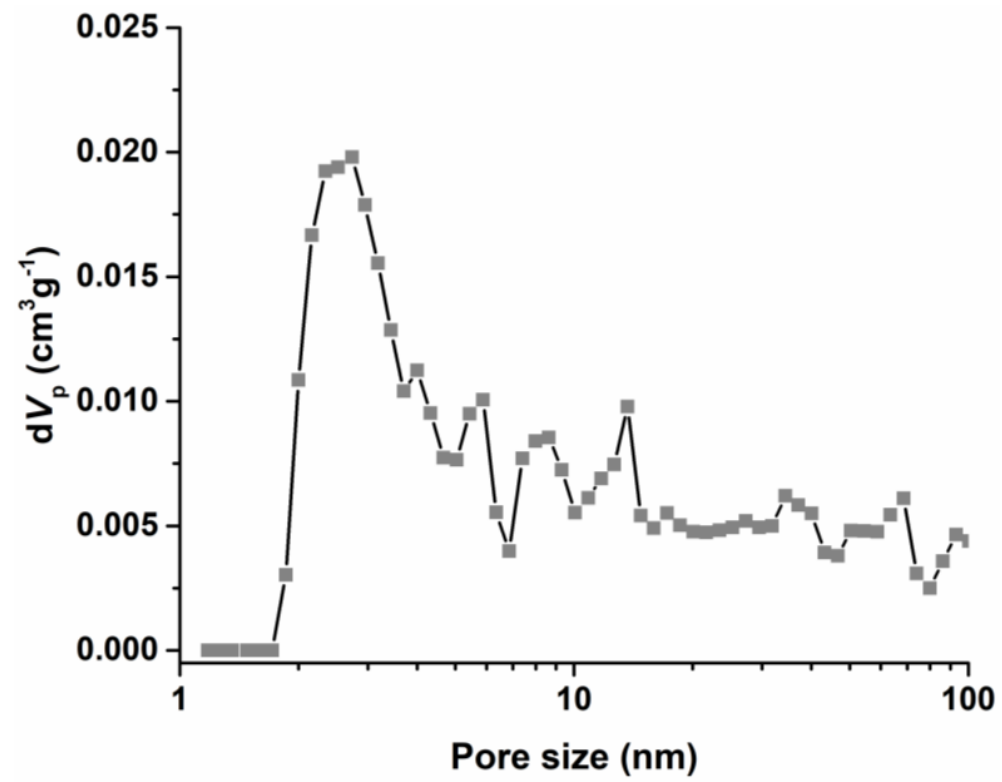

Figure S6. Pore-size-distribution of CON-LDU2 calculated from the adsorption isotherm with NLDFT method. 


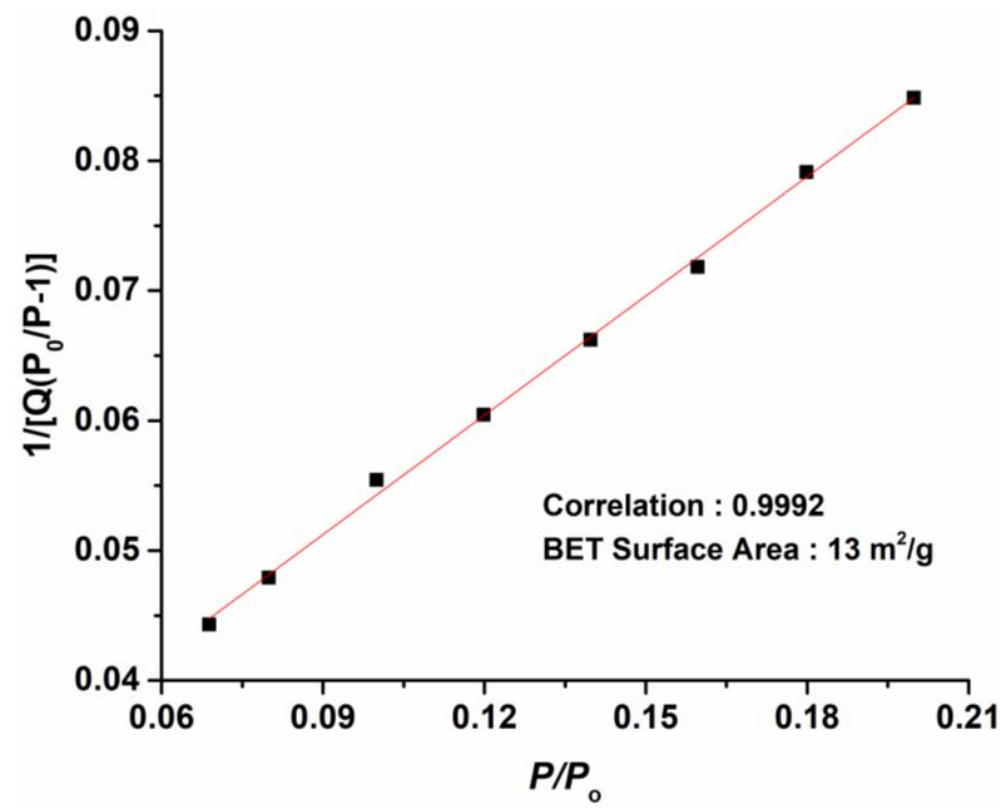

Figure S7. BET surface area plot for CON-LDU2 calculated from the adsorption isotherm. 
H. Thermogravimetric Analysis

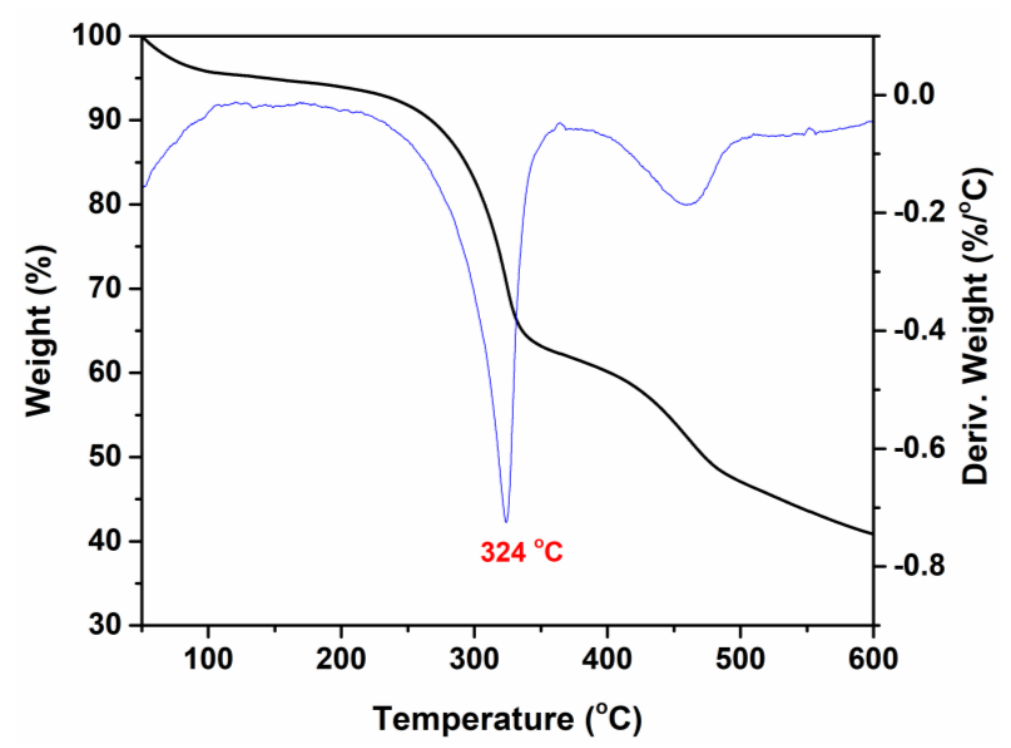

Figure S8. The TGA curve of CON-LDU2. 


\section{Scanning Electron Micrograph}

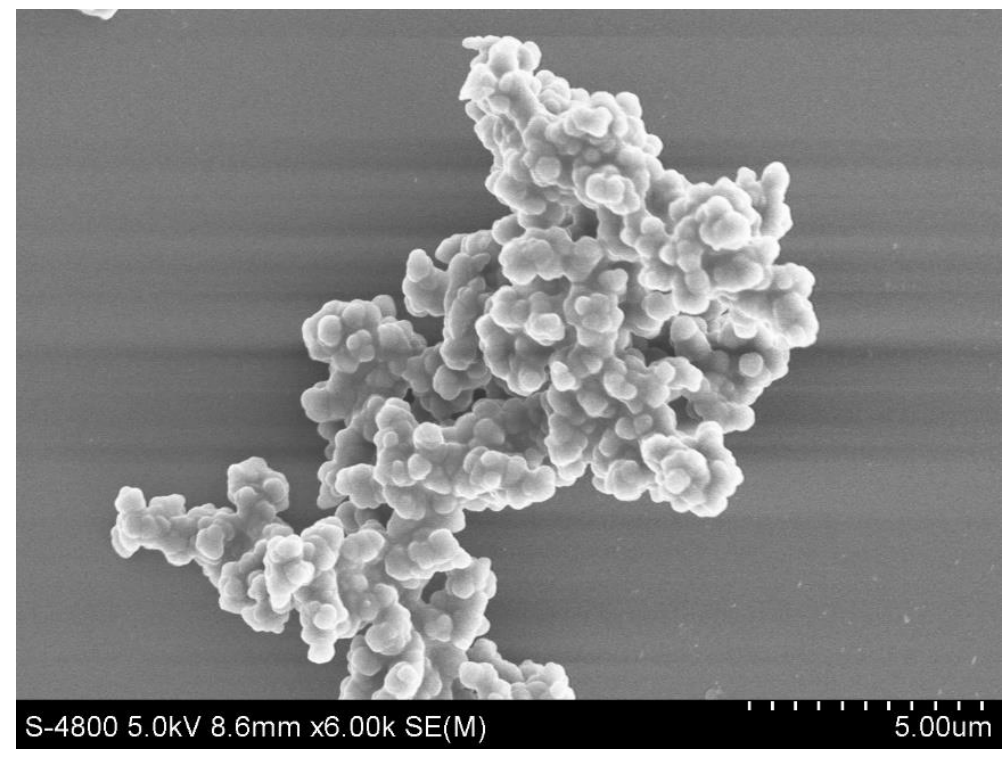

Figure S9. The SEM image of CON-LDU2. 


\section{J. X-ray Photoelectron Spectroscopy}

a.

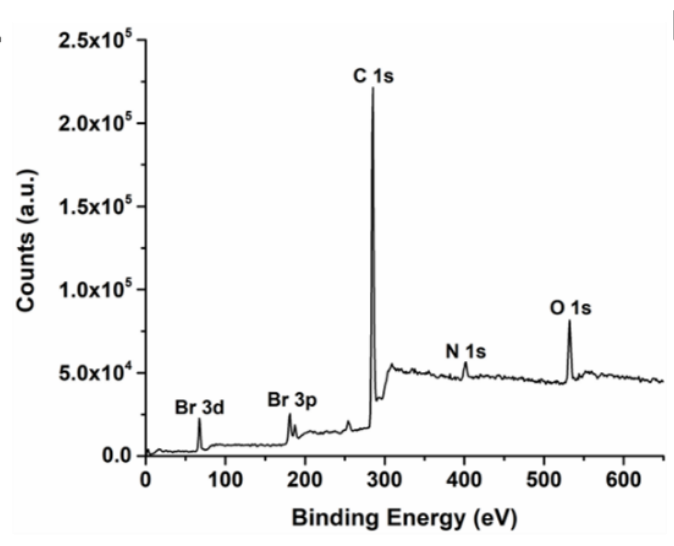

C.

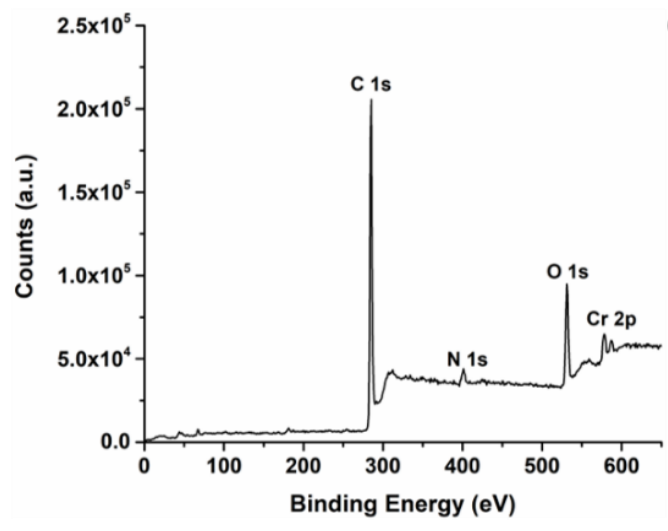

e.

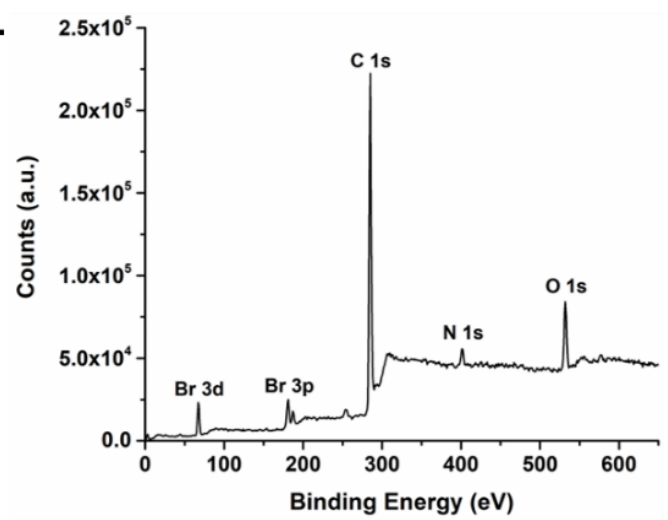

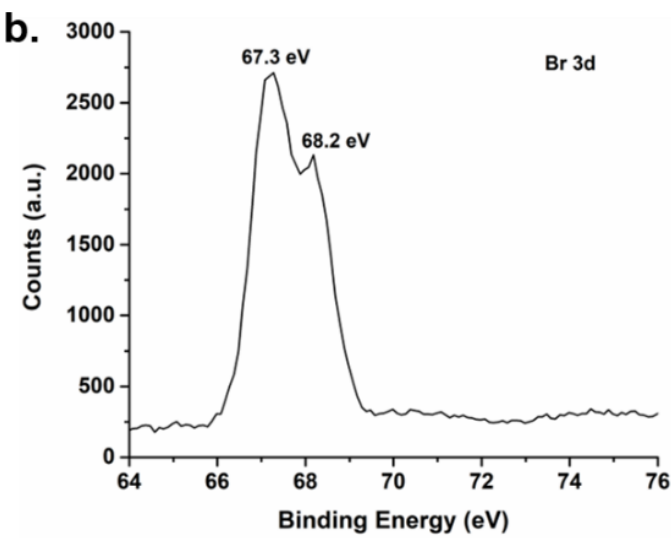


Figure S10. XPS spectra of CON-LDU2 (a. widescan, b. Br 3d), CON-LDU2-Cr (c. widescan, d. Cr 2p), and Regenerated CON-LDU2 (e. widescan, f. Br 3d). 


\section{K. Fluorescence Detection of $\mathrm{Cr}_{2} \mathrm{O}_{7}{ }^{2-}$}

Firstly, a homogeneous suspension was obtained via dispersing CON-LDU2 (20 $\mathrm{mg}$ ) in $50 \mathrm{~mL}$ of deionized water, then the solution was stirred for $30 \mathrm{~min}$ and ultrasonicated for $30 \mathrm{~min}$ respectively. The suspension of CON-LDU2 exhibited a strong emission at $570 \mathrm{~nm}$ under the excitation at $382 \mathrm{~nm}$.

Generally, $2 \mathrm{~mL}$ of CON-LDU2 suspension was added in a quartz cuvette via a pipette, and the fluorescence intensity was recorded with a fluorescence spectrophotometer. The fluorescence titration was performed by gradual addition of $\mathrm{Cr}_{2} \mathrm{O}_{7}{ }^{2-}$ solution to the suspension of CON-LDU2 $(2 \mathrm{~mL})$ and recorded the fluorescence intensity. The concentration of $\mathrm{Cr}_{2} \mathrm{O}_{7}{ }^{2-}$ was increased from 0 to $211 \mu \mathrm{M}$, the fluorescence of CON-LDU2 was gradually quenched.

To test the selectivity, $2 \mathrm{~mL}$ of suspension was added in a quartz cuvette, and 150 $\mu \mathrm{L}$ of $\mathrm{NaX}$ or $\mathrm{KX}$ aqueous solution $\left(3.4 \mathrm{mM}, \mathrm{X}=\mathrm{SO}_{4}{ }^{2-}, \mathrm{Br}^{-}, \mathrm{NO}_{2}{ }^{-}, \mathrm{PO}_{4}{ }^{3-}, \mathrm{OAc}^{-}, \mathrm{HPO}_{4}{ }^{2-}\right.$, $\mathrm{BF}_{4}^{-}, \mathrm{HSO}_{3}{ }^{-}, \mathrm{HCO}_{3}{ }^{-}, \mathrm{CO}_{3}{ }^{2-}, \mathrm{NO}_{3}{ }^{-}, \mathrm{Cl}^{-}$, and $\left.\mathrm{Cr}_{2} \mathrm{O}_{7}{ }^{2-}\right)$ was separately added via a pipette. The fluorescence intensities were recorded on a fluorescence spectrophotometer.

The influence of the disturbing anions on the detecting efficiency of $\mathrm{Cr}_{2} \mathrm{O}_{7}{ }^{2-}$ was investigated. Firstly, $150 \mu \mathrm{L}$ of different disturbing anions aqueous solution (including $\mathrm{SO}_{4}{ }^{2-}, \mathrm{Br}^{-}, \mathrm{NO}_{2}{ }^{-}, \mathrm{PO}_{4}{ }^{3-}, \mathrm{OAc}^{-}, \mathrm{HPO}_{4}{ }^{2-}, \mathrm{BF}_{4}{ }^{-}, \mathrm{HSO}_{3}{ }^{-}, \mathrm{HCO}_{3}{ }^{-}, \mathrm{CO}_{3}{ }^{2-}, \mathrm{NO}_{3}{ }^{-}, \mathrm{Cl}^{-}$, the concentration for each anion is $3.4 \mathrm{mM}$ ) were separately added to the suspension of CON-LDU2, and the fluorescence intensities were recorded. Then, to the suspensions containing the disturbing anions were added $150 \mu \mathrm{L}$ of $\mathrm{Cr}_{2} \mathrm{O}_{7}{ }^{2-}$ aqueous solution (3.4 $\mathrm{mM}$ ), and the fluorescence intensity was measured. 


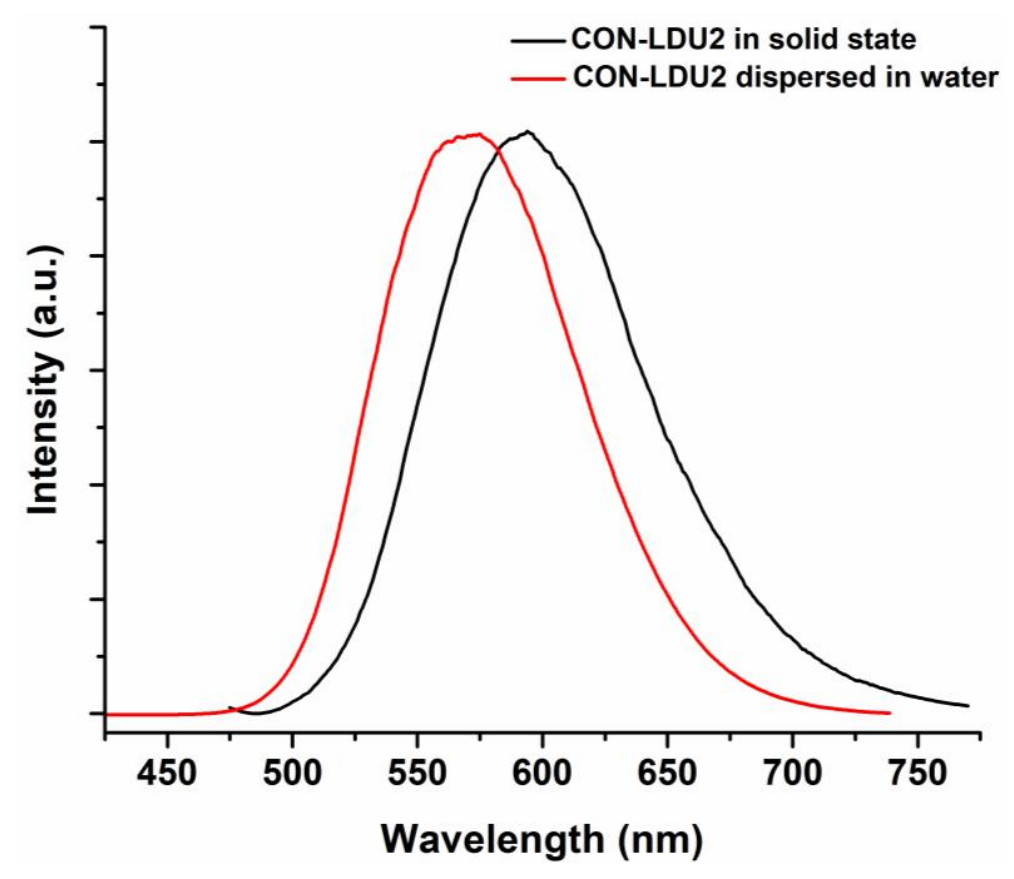

Figure S11. Fluorescence spectra of CON-LDU2 in solid state and dispersed in water.

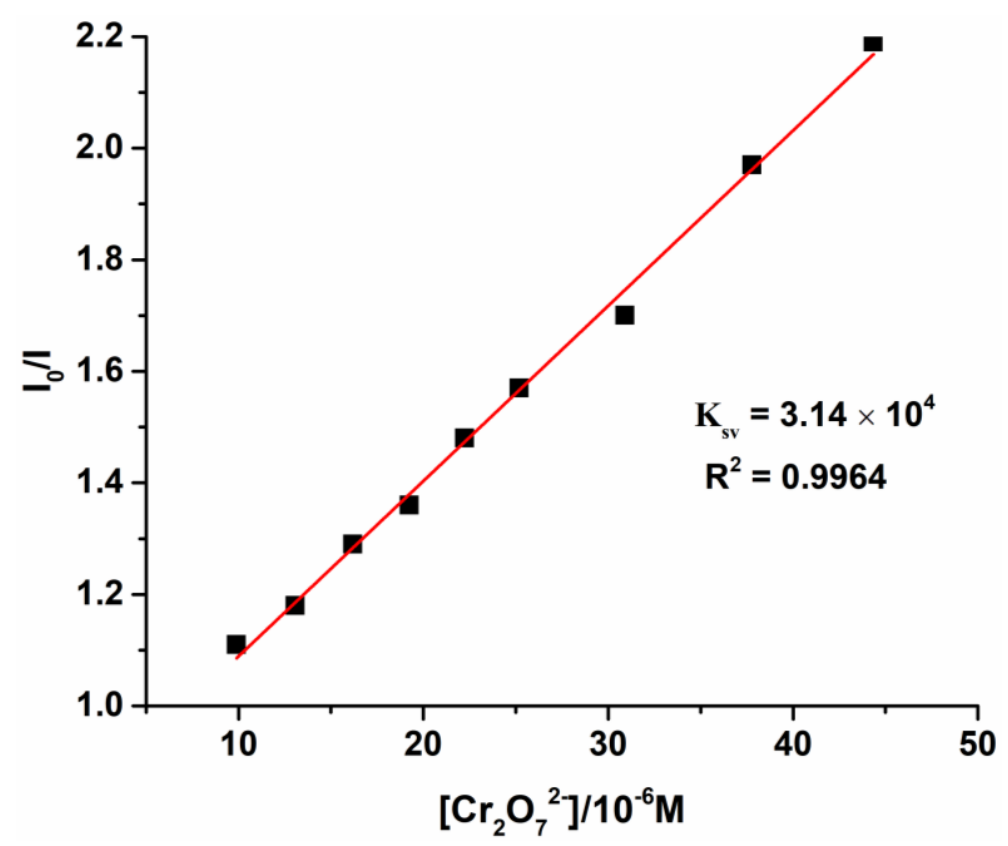

Figure S12. Stern-Volmer plot of CON-LDU2 quenched by $\mathrm{Cr}_{2} \mathrm{O}_{7}{ }^{2-}$. 


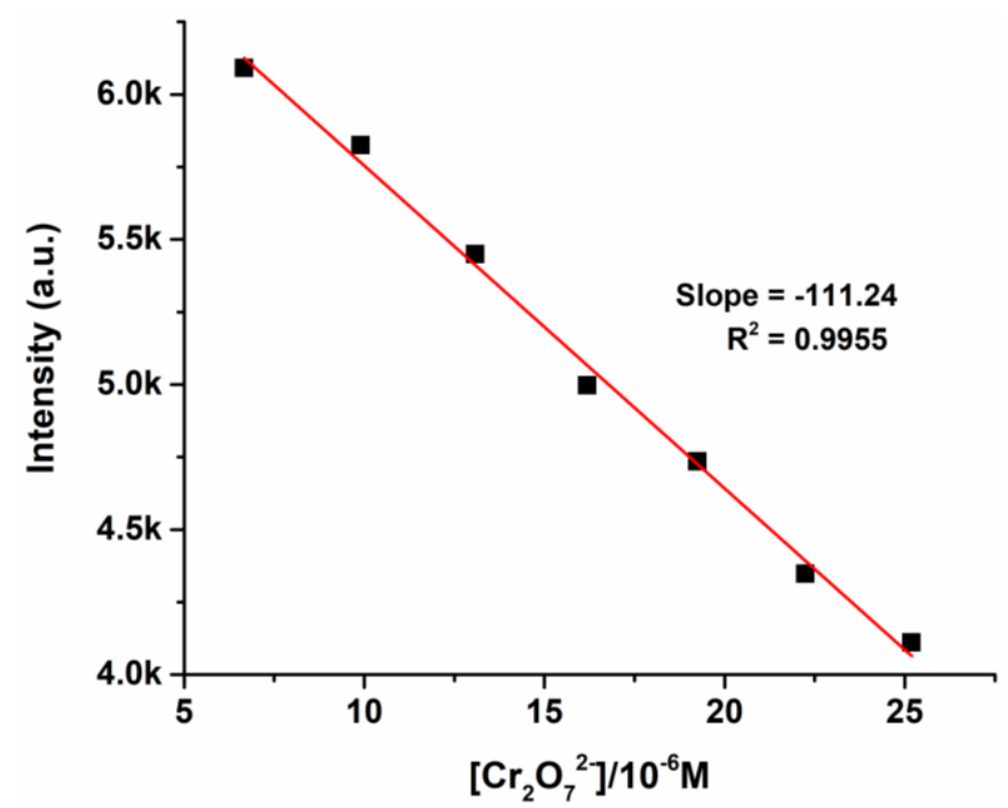

Figure S13. The linear fitting for the fluorescence intensities of CON-LDU2 versus the concentration of $\mathrm{Cr}_{2} \mathrm{O}_{7}{ }^{2-}$. The linear fitting gave the slope (S) is $111.24 \mu \mathrm{M}^{-1}$. The limit of detection (LOD) is calculated as $0.65 \mu \mathrm{M}$ by using equation $\mathrm{LOD}=3 \sigma / \mathrm{S}$, where $\sigma$ is standard deviation of fluorescence intensity of blank samples ( $\sigma$ is determined as 24.12).

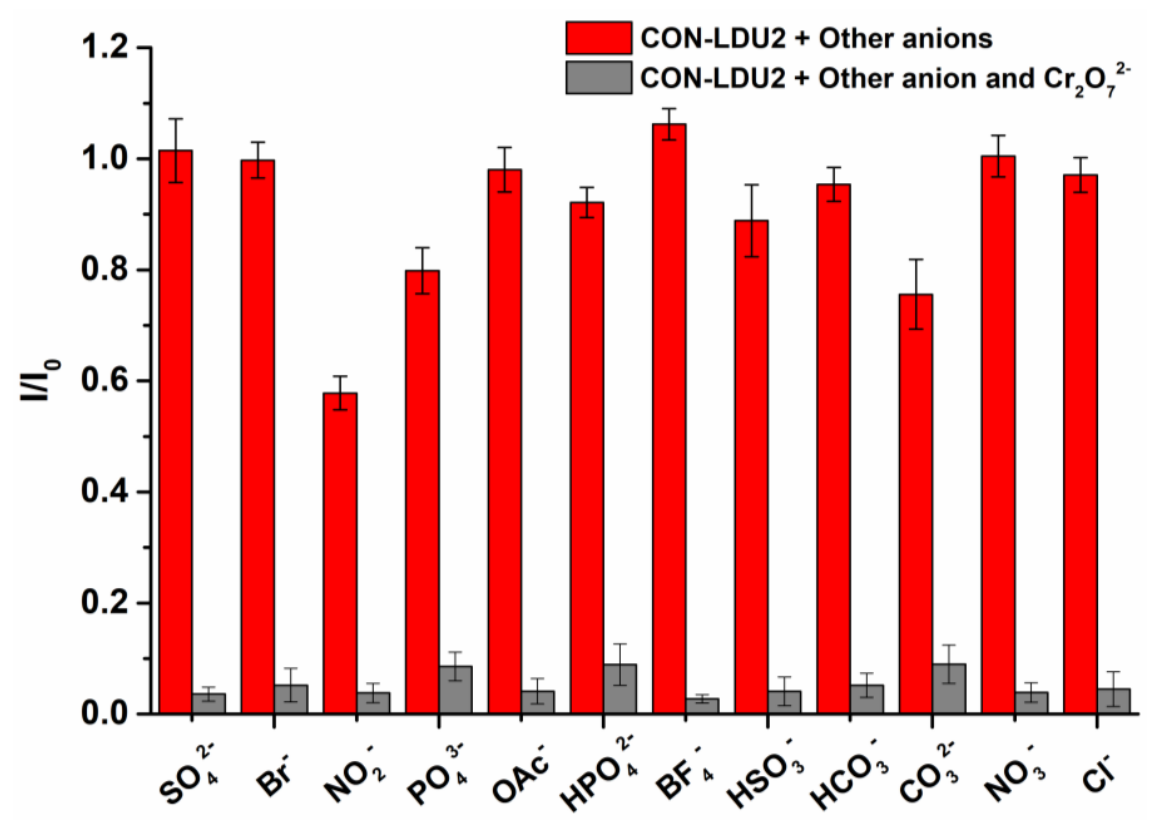

Figure S14. The fluorescence intensities of CON-LDU2 in the presence of competing anions, and in the presence of competing anions and $\mathrm{Cr}_{2} \mathrm{O}_{7}{ }^{2-}$. 


\section{Adsorption of $\mathrm{Cr}_{2} \mathrm{O}_{7}{ }^{2-}$}

Generally, CON-LDU2 (3 mg) was dispersed in $5 \mathrm{~mL}$ of $\mathrm{K}_{2} \mathrm{Cr}_{2} \mathrm{O}_{7}$ aqueous solution (200 ppm) and magnetically stirred under room temperature for a certain time. The solution was measured with UV-vis spectrophotometer after removal of adsorbent with a syringe filter (PTFE, $0.45 \mu \mathrm{m}$ ) and diluted to a proper concentration with deionized water. The adsorption percentage was obtained by comparing the maximum absorbance $(\lambda=257 \mathrm{~nm})$ with the original $\mathrm{K}_{2} \mathrm{Cr}_{2} \mathrm{O}_{7}$ aqueous solution.

$$
Q_{t}=\left(\frac{C_{0}-C_{t}}{m}\right) \times V
$$

where $Q_{t}$ is the adsorption capacity at contact time $t, C_{0}$ is the initial concentration of $\mathrm{K}_{2} \mathrm{Cr}_{2} \mathrm{O}_{7}$ solution, $C_{t}$ is the concentration of $\mathrm{K}_{2} \mathrm{Cr}_{2} \mathrm{O}_{7}$ at time $t, m$ is the mass of $\mathbf{C O N}$ LDU2, and the $V$ is the volume of solution.

The kinetic data were fitted with pseudo-second order models.

$$
\frac{t}{Q_{t}}=\frac{1}{k_{2} Q_{e}^{2}}+\frac{t}{Q_{e}}
$$

where $k_{2}$ is the kinetic constant of pseudo-second order.

The adsorption capacity was evaluated by immersing CON-LDU2 (5 mg) into 6 $\mathrm{mL}_{\text {of }} \mathrm{K}_{2} \mathrm{Cr}_{2} \mathrm{O}_{7}$ aqueous solution with different initial concentration (100, 200, 500, 800, and $1000 \mathrm{ppm})$. The solution was stirred for $2.5 \mathrm{~h}$ under room temperature. Then the solution was extracted and filtered with a syringe filter (PTFE, $0.45 \mu \mathrm{m}$ ). After being diluted with deionized water, the solution was measured with UV-vis spectrophotometer. The equilibrium adsorption capacity $\left(Q_{e}\right)$ was calculated by using the following equation.

$$
Q_{e}=\left(\frac{C_{0}-C_{e}}{m}\right) \times V
$$

where the $C_{e}$ is the equilibrium concentration of $\mathrm{K}_{2} \mathrm{Cr}_{2} \mathrm{O}_{7}$ solution.

The adsorption isotherm of $\mathrm{Cr}_{2} \mathrm{O}_{7}^{2-}$ was fitted with LangmuirEXT, Langmuir, and Freundlich models respectively.

LangmuirEXT equation:

$$
Q_{e}=\frac{Q_{m} K_{S} C_{e}^{\gamma}}{1+K_{S} C_{e}^{\gamma}}
$$


Langmuir equation:

$$
Q_{e}=\frac{Q_{m} K_{L} C_{e}}{1+K_{L} C_{e}}
$$

Freundlich equation:

$$
Q_{e}=K_{F} C_{e}^{1 / n}
$$

where $Q_{m}$ is the maximum adsorption capacity, $K_{S}$ and $\gamma$ are the constants of LangmuirEXT model, $K_{L}$ is the constant of Langmuir model, $K_{F}$ and $n$ are constants of Freundlich model.

The effect of competing ions was investigated by immersing CON-LDU2 (3 mg) in $5 \mathrm{~mL}$ of $\mathrm{K}_{2} \mathrm{Cr}_{2} \mathrm{O}_{7}$ aqueous solution (200 ppm) which contain 10- or 50-fold of each ion $\left(\mathrm{Cl}^{-}, \mathrm{Br}^{-}, \mathrm{NO}_{3}{ }^{-}\right.$, and $\left.\mathrm{SO}_{4}{ }^{2-}\right)$ respectively. The solution was stirred for $1 \mathrm{~h}$ under room temperature. Then the solution was extracted and filtered with a syringe filter (PTFE, $0.45 \mu \mathrm{m})$. After being diluted with deionized water, the solution was measured with UV-Vis spectrophotometer. The adsorption percentage was obtained by comparing the maximum absorbance $(\lambda=257 \mathrm{~nm})$ with the original $\mathrm{K}_{2} \mathrm{Cr}_{2} \mathrm{O}_{7}$ aqueous solution.

The effect of $\mathrm{pH}$ values of the solution was carried out by immersing CON-LDU2 (3 mg) in $5 \mathrm{~mL} \mathrm{~K}_{2} \mathrm{Cr}_{2} \mathrm{O}_{7}$ aqueous solution (200 ppm) with different $\mathrm{pH}$ values. The $\mathrm{pH}$ values of the solution were adjusted via adding $0.1 \mathrm{M} \mathrm{HCl}$ and $0.1 \mathrm{M} \mathrm{NaOH}$. After stirring for $1 \mathrm{~h}$, the solution was extracted and filtered with a syringe filter (PTFE, 0.45 $\mu \mathrm{m})$, the $\mathrm{Cr}(\mathrm{VI})$ contents were analyzed by using ICP-OES.

The reusability of CON-LDU2 was tested by immersing CON-LDU2 (30 mg) in $50 \mathrm{~mL}$ of $\mathrm{K}_{2} \mathrm{Cr}_{2} \mathrm{O}_{7}$ aqueous solution (200 ppm). After the adsorption, CON-LDU2-Cr was filtered and stirred in $\mathrm{NaBr}$ aqueous solution $(0.8 \mathrm{~mol} / \mathrm{L})$. The Regenerated CONLDU2 was filtered and washed with deionized water and ethanol. The Regenerated CON-LDU2 was reused in next cycle under the same conditions. 


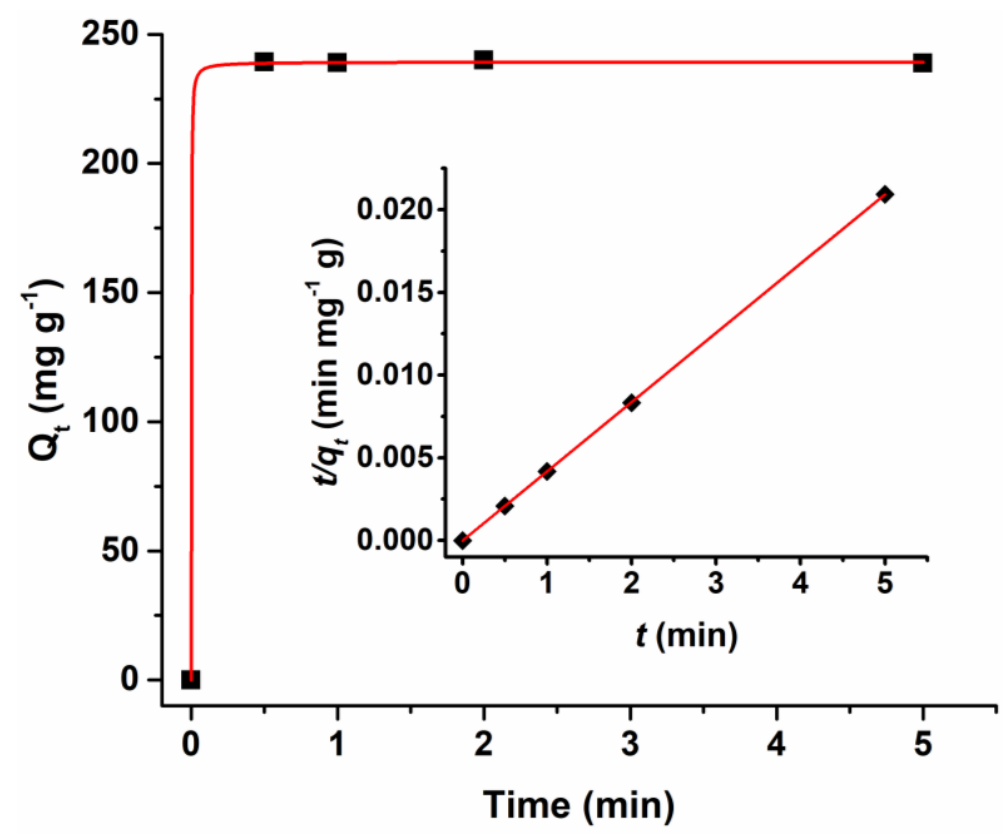

\begin{tabular}{|c|c|c|}
\hline Fitting model & Parameter & $\begin{array}{c}\text { correlation coeffi- } \\
\text { cient }\end{array}$ \\
\hline Pseudo-second order & $\mathrm{Q}_{\mathrm{e}}=238.7 \mathrm{mg} \mathrm{g}^{-1}$ \\
$\mathrm{k}_{2}=1.784 \mathrm{~g} \mathrm{mg}^{-1} \mathrm{~min}^{-1}$ & $\mathrm{R}^{2}>0.9999$ \\
\hline
\end{tabular}

Figure S15. The kinetics for adsorption of $\mathrm{Cr}_{2} \mathrm{O}_{7}{ }^{2-}$ fitted by pseudo-second order model. 


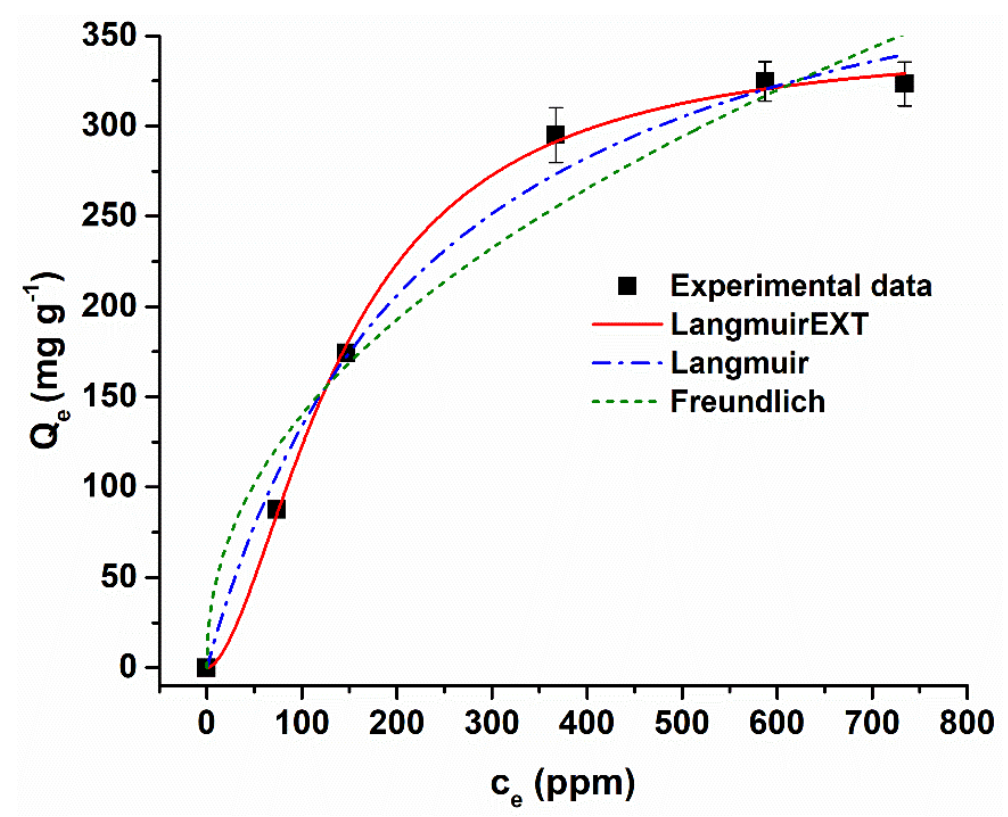

\begin{tabular}{|c|c|c|}
\hline Fitting model & Parameter & correlation coefficient \\
\hline \multirow{2}{*}{ LangmuirEXT } & $\mathrm{Q}_{\mathrm{m}}=348.8 \mathrm{mg} \mathrm{g}^{-1}$ & \\
& $\mathrm{~K}_{\mathrm{S}}=2.00 \times 10^{-4}$ & $\mathrm{R}^{2}=0.9979$ \\
& $\gamma=1.72$ & \\
\hline Langmuir & $\mathrm{Q}_{\mathrm{m}}=448.7 \mathrm{mg} \mathrm{g}^{-1}$ & $\mathrm{R}^{2}=0.9879$ \\
\hline Freundlich & $\mathrm{K}_{\mathrm{L}}=4.25 \times 10^{-3}$ & \\
\hline & $\mathrm{K}_{\mathrm{F}}=16.82$ & $\mathrm{R}^{2}=0.9610$ \\
\hline
\end{tabular}

Figure S16. The adsorption isotherm of $\mathrm{Cr}_{2} \mathrm{O}_{7}{ }^{2-}$ fitted with different models. As listed above, the correlation coefficient obtained from LangmuirEXT model is higher than other two models, suggesting LangmuirEXT model can well describe the adsorption process. 


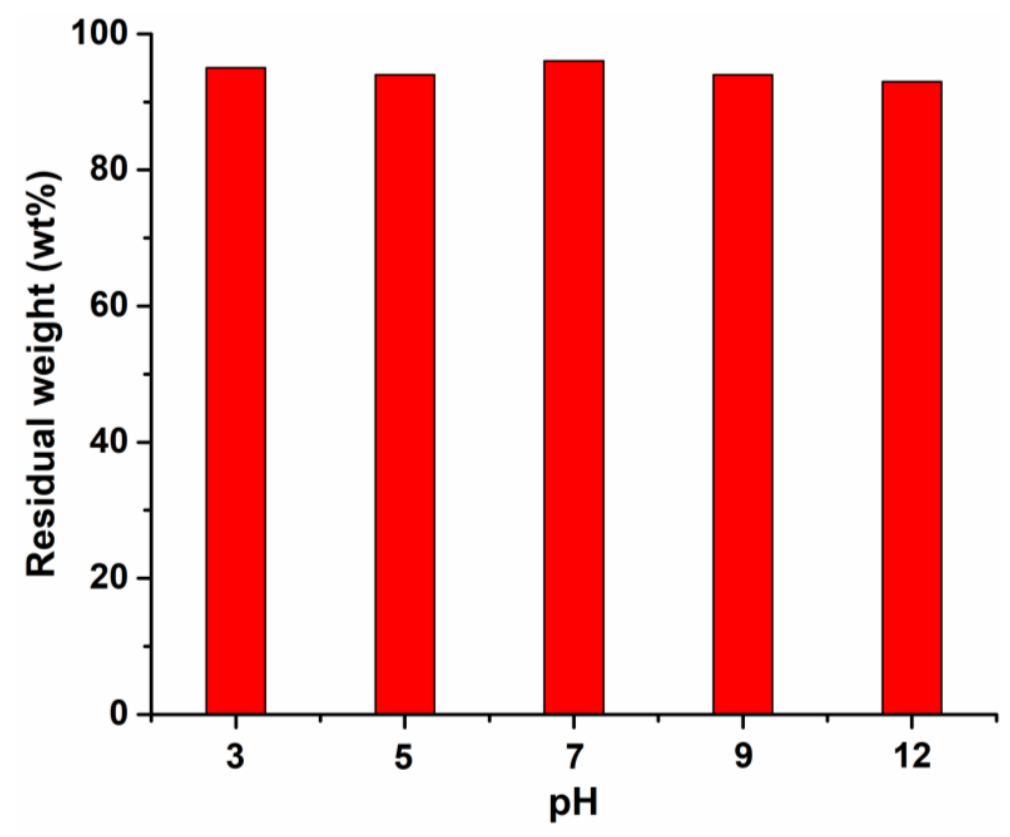

Figure S17. The weight residual percentages of CON-LDU2 after treating in aqueous solution with different $\mathrm{pH}$ values.

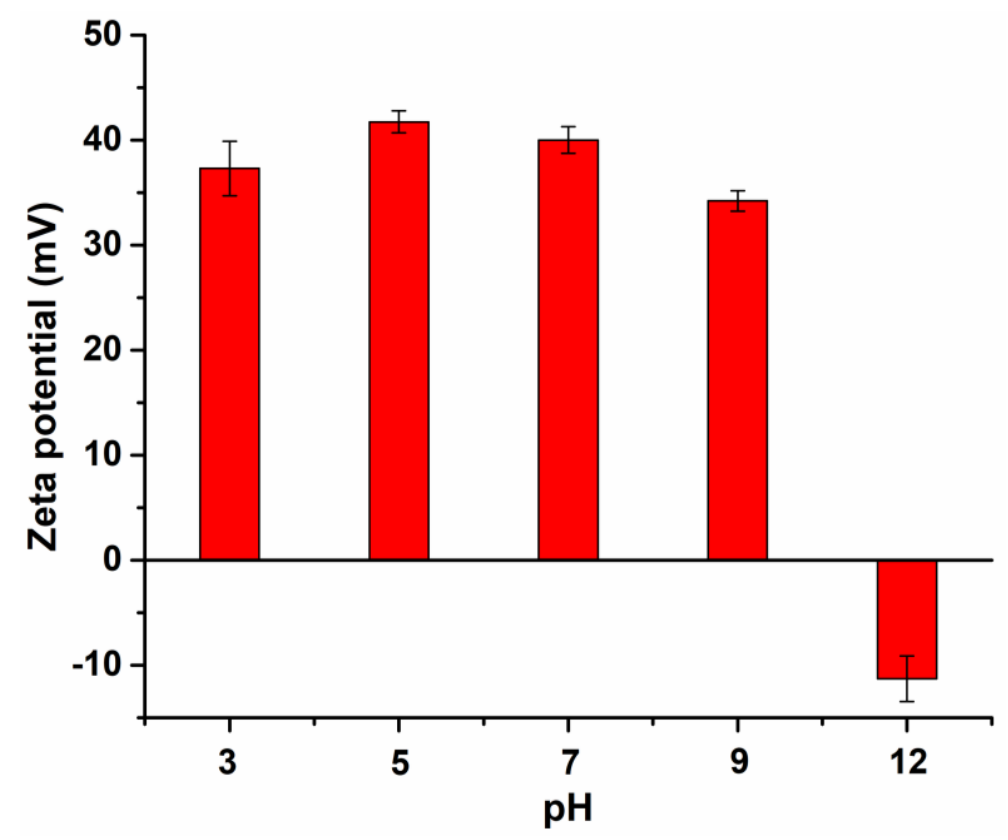

Figure S18. Zeta potentials of CON-LDU2 at different $\mathrm{pH}$ values. 


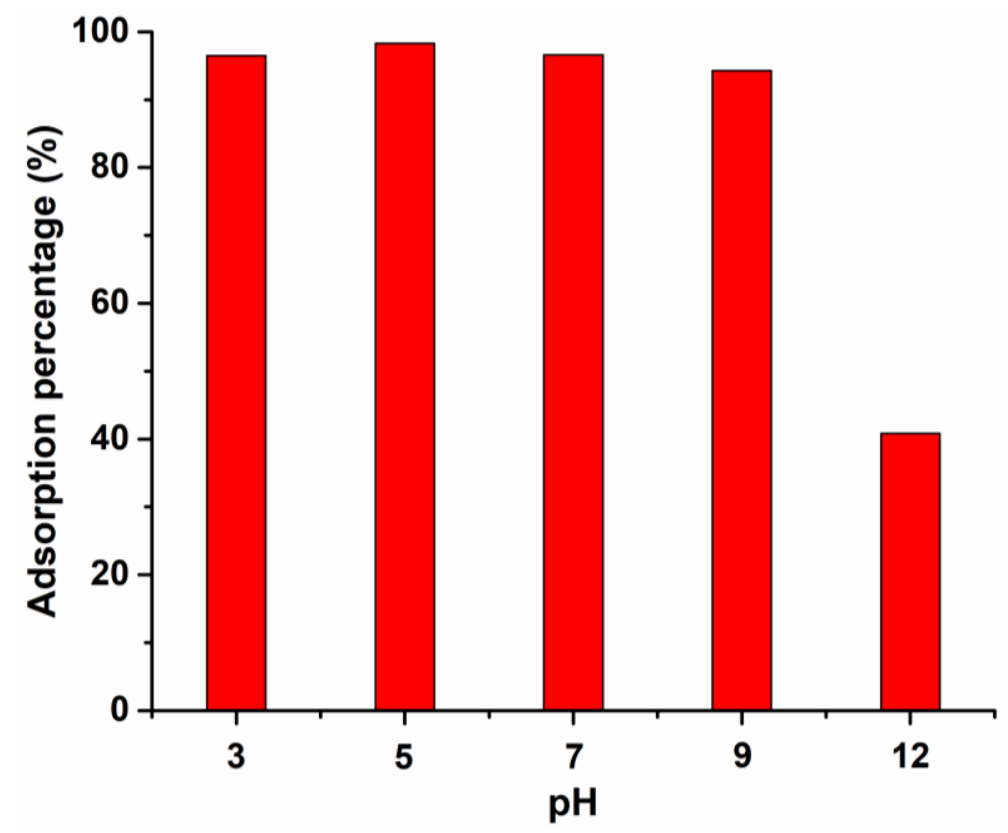

Figure S19. The adsorption percentages for $\mathrm{Cr}(\mathrm{VI})$ at different $\mathrm{pH}$ values. 
Table S1. Comparison of $\mathrm{Cr}_{2} \mathrm{O}_{7}{ }^{2-}$ adsorption capacity of CON-LDU2 with other adsorbents.

\begin{tabular}{|c|c|c|c|}
\hline Entry & Adsorbents & $\begin{array}{c}\text { Adsorption } \\
\text { capacity (mg/g) }\end{array}$ & Ref. \\
\hline 1 & PVIm-6-SCD & 457.8 & {$[1]$} \\
\hline 2 & IMIP-Br & 318 & {$[2]$} \\
\hline 3 & ZJU-101 & 245 & [3] \\
\hline 4 & MOR-1-HA & 242 & {$[4]$} \\
\hline 5 & $\mathrm{ABT} \cdot 2 \mathrm{ClO}_{4}$ & 213 & {$[5]$} \\
\hline 6 & $1-\mathrm{SO}_{4}$ & 166 & [6] \\
\hline 7 & $1-\mathrm{Br}$ & 128 & [7] \\
\hline 8 & FIR-54 & 103.1 & [8] \\
\hline 9 & FIR-53 & 74.2 & [8] \\
\hline 10 & ZIF-67 & 27.7 & [9] \\
\hline 11 & POP-Im1 & 172 & {$[10]$} \\
\hline 12 & $\mathrm{NH}_{2}$-TNTs & 319.5 & [11] \\
\hline 13 & $\begin{array}{c}\beta-\mathrm{CD} \text { and quaternary ammonium } \\
\text { groups modified cellulose }\end{array}$ & 126.8 & [12] \\
\hline 14 & $\begin{array}{c}\text { Modified magnetic chitosan } \\
\text { chelating }\end{array}$ & 121.5 & [13] \\
\hline 15 & $\mathrm{CON}-1$ & 293 & [14] \\
\hline 16 & CON-LDU2 & 325 & This work \\
\hline
\end{tabular}




\section{References}

(1) Xie, Y.; Lin, J.; Liang, J.; Li, M.; Fu, Y.; Wang, H.; Tu, S.; Li, J. Chem. Eng. J. 2019, 378, 122107.

(2) Wang, Y.; Zhao, H.; Li, X.; Wang, R. J. Mater. Chem. A 2016, 4, 12554.

(3) Zhang, Q.; Yu, J.; Cai, J.; Zhang, L.; Cui, Y.; Yang, Y.; Chen, B.; Qian, G. Chem. Commun. 2015, 51, 14732 .

(4) Rapti, S.; Pournara, A.; Sarma, D.; Papadas, I. T.; Armatas, G. S.; Tsipis, A. C.; Lazarides, T.; Kanatzidis, M. G.; Manos, M. J. Chem. Sci. 2016, 7, 2427.

(5) Li, X.; Xu, H.; Kong, F.; Wang, R. Angew. Chem. Int. Ed. 2013, 52, 13769.

(6) Desai, A. V.; Manna, B.; Karmakar, A.; Sahu, A.; Ghosh, S. K. Angew. Chem. Int. Ed. 2016, 55, 7811.

(7) Lv, X.-X.; Shi, L.-L.; Li, K.; Li, B.-L.; Li, H.-Y. Chem. Commun. 2017, 53, 1860.

(8) Fu, H.-R.; Xu, Z.-X.; Zhang, J. Chem. Mater. 2015, 27, 205.

(9) Li, X.; Gao, X.; Ai, L.; Jiang, J. Chem. Eng. J. 2015, 274, 238.

(10) Su, Y.; Wang, Y.; Li, X.; Li, X.; Wang, R. ACS Appl. Mater. Interfaces 2016, 8, 18904.

(11) Wang, L.; Liu, W.; Wang, T.; Ni, J. Chem. Eng. J. 2013, 225, 153.

(12) Zhou, Y.; Jin, Q.; Zhu, T.; Akama, Y. J. Hazard. Mater. 2011, 187, 303.

(13) Abou El-Reash, Y. G.; Otto, M.; Kenawy, I. M.; Ouf, A. M. Int. J. Biol. Macromol. 2011, 49, 513.

(14) Li, Z.-J.; Xue, H.-D.; Zhang, Y.-Q.; Hu, H.-S.; Zheng, X.-D. New J. Chem. 2019, $43,11604$. 